\title{
POLÍTICA HABITACIONAL E NEGÓCIOS IMOBILIÁRIOS EM PIRACICABA: INTERESSES PÚBLICOS E PRIVADOS ${ }^{1}$
}

\author{
Estevam Vanale Otero ${ }^{2}$
}

\begin{abstract}
Resumo: A partir dos anos 2000 a produção do espaço urbano na cidade média de Piracicaba acelerou-se significativamente. Assistiu-se à explosão da oferta de uma série de produtos imobiliários, voltados a um amplo leque de potenciais consumidores, promovendo a modificação da paisagem e borrando os limites entre o rural e o urbano, com profundas implicações na definição dos valores de uso e dos valores de troca das distintas localizações do território municipal. Condutor do processo, o circuito imobiliário vem adquirindo proeminência cada vez maior em sua economia local, moldando as legislações urbanísticas conforme os interesses envolvidos na ampliação dos valores fundiários e imobiliários. No presente artigo é desenvolvida análise sobre a proposta da Operação Urbana Consorciada Corumbataí, grande empreendimento habitacional de interesse social na periferia de Piracicaba, e suas lógicas nesse quadro de dominância dos interesses imobiliários na política urbana municipal.
\end{abstract}

Palavras-chave: mercado imobiliário; produção do espaço urbano; cidades médias; Programa Minha Casa Minha Vida

\section{HOUSING POLICY AND REAL ESTATE BUSINESS IN PIRACICABA: PUBLIC AND PRIVATE INTERESTS}

\begin{abstract}
Since the 2000s, the production of urban space in medium-sized citiy of Piracicaba has been accelerating significantly. We have seen the explosion in the supply of a lot of housing products, focused on a wide range of potential consumers, promoting the landscape changes and blurring the boundaries between rural and urban, with profound entailments for the definition of the use values and exchange values on the different localizations within the municipal territory. The real estate market, as a process conductor, has been increasing its prominence in its local economy, shaping the urban legislation as the interests involved in the expansion of land and real estate values. This article analyzes the purpose of the Consortiated Urban Operation Corumbataí, large housing development of social interest on the outskirts of Piracicaba, and their logic regarding real estate interests in municipal urban policy.

Keywords: real estate market; production of urban space; medium-sized cities; Minha Casa Minha Vida Program

\footnotetext{
${ }^{1}$ Este artigo é fruto do conjunto de pesquisas desenvolvidas no âmbito do Grupo de Estudo e Pesquisa "Negócios Imobiliários e Dispersão Urbana no Interior Paulista", do Curso de Arquitetura e Urbanismo da Universidade Metodista de Piracicaba, contando com apoio e suporte dessa Instituição no desenvolvimento das investigações. O Grupo desenvolve estudos acerca da atividade imobiliária e da produção do espaço urbano nos municípios integrantes do Aglomerado Urbano de Piracicaba. O autor agradece às arquitetas Bianca Crepaldi, Bárbara Caetano Damasceno e Bruna Silva Wanderley, pelas valiosas contribuições no desenvolvimento das pesquisas e nas discussões envolvidas na reflexão que resultou no presente artigo.

${ }^{2}$ Unimep - Universidade Metodista de Piracicaba. E-mail: estevamotero@yahoo.com
} 


\section{INTRODUÇÃO}

Cada vez mais a produção do espaço urbano vem se tornando elemento chave no processo de acumulação capitalista global, absorvendo grandes quantidades de capital sobreacumulado, à procura de alternativas rentáveis para a extração de juros, lucros e renda (HARVEY, 2014; 2013; 2011). A produção - e o consumo - do espaço urbano converteu-se numa das dinâmicas centrais das economias locais, em cidades dos mais diferentes portes demográficos, com profundas implicações na (re) estruturação de seus espaços intraurbanos.

Evidentemente, esses processos são distintos em Nova York e Londres, São Paulo e Rio de Janeiro ou Piracicaba e Limeira. Entretanto, a centralidade adquirida pelo imobiliário em diferentes escalas geográficas do mundo capitalista e, notadamente nas cidades do interior paulista, vem promover impactos sensíveis em sua organização interna, constituindo espaços com formas e conteúdos sociais muito distintos do que se divisava até então. A cidade converte-se numa mercadoria privilegiada nesse momento, fronteira de valorização de capitais locais e forâneos, em que os valores de troca dos espaços construídos ganham relevo sobre os valores de uso.

Nesse contexto, em que a produção imobiliária se torna quantitativamente relevante tanto em termos econômicos quanto em relação aos seus impactos urbanos, faz-se necessário apreender as formas assumidas por essa produção tanto quanto a sua lógica econômica, da qual os imóveis não são meramente um reflexo, mas um importante ativo (FIX, 2011).

Para levar a cabo a interpretação sobre a produção do espaço urbano contemporâneo nas cidades do interior paulista e, mais especificamente, daquelas inseridas no Aglomerado Urbano de Piracicaba, é preciso compreender suas especificidades frente a processos que, ainda que sistêmicos na atual quadra do capitalismo global, apresentam resultados distintos em diferentes contextos urbanos, sociais e econômicos.

A produção imobiliária em Piracicaba, cidade aqui tomada para uma análise mais acurada, vem resultando numa significativa reestruturação de seu espaço intraurbano, tanto pelos impactos quantitativos, resultante do porte dos empreendimentos implantados, quanto pelas novas tipologias introduzidas e consolidadas ao longo das últimas duas décadas. A ampliação da atividade imobiliária nesse contexto relaciona-se tanto às transformações no quadro do desenvolvimento capitalista nacional (e global) quanto a determinantes eminentemente locais, em que se constituíram coalizões de interesse de modo a promover a "máquina de crescimento" local (LOGAN; MOLOTCH, 2007).

No presente artigo será analisada a recente produção imobiliária em Piracicaba, cidade que figura no topo de variados rankings relacionados à produção do espaço urbano no último período. Especial atenção é dedicada, aqui, à promoção habitacional realizada no âmbito do Programa Minha Casa Minha Vida (PMCMV), observando que a expressiva produção de moradias e novos parcelamentos do solo veio articulada à constituição de uma notável "máquina de crescimento", que veio promover o próprio espaço a uma das mais importantes mercadorias locais.

Para tanto, o trabalho articula-se em três partes complementares: na primeira seção deste artigo são apresentadas informações relativas ao quadro Estudos Geográficos, Rio Claro, 15(2): p-p, jul./dez. 2017 (ISSN 1678—698X) 
contemporâneo da urbanização em Piracicaba, explorando os aspectos sociais, econômicos e demográficos que a caracterizam neste princípio de século XXI. Em seguida discorremos sobre a produção imobiliária recente no município, com foco especial na produção de habitação de interesse social e de mercado popular. Por fim, analisamos a proposta apresentada pelo Executivo Municipal, por meio do Projeto de Lei Complementar (PLC) 015/2017, para a instituição da Operação Urbana Consorciada (OUC) Corumbataí, destinada à produção de 3.500 novas unidades habitacionais de interesse social no extremo norte da cidade.

\section{O QUADRO CONTEMPORÂNEO DA URBANIZAÇÃO EM PIRACICABA}

O município de Piracicaba conta em 2018, segundo estimativas do IBGE, com uma população total de 385.155 habitantes, dos quais 378.029 residiriam em áreas urbanas, representando uma taxa de urbanização de pouco mais de $98 \%$. Capital Regional de Nível C, Piracicaba, a exemplo de outros centros urbanos de mesmas características, constitui-se polo de uma rede urbana que congrega 17 municípios, abrigando pouco menos da metade dos habitantes de sua rede urbana, tanto quando tomados os valores totais quanto se observados apenas os residentes no meio urbano (IBGE, 2008).

As características atuais de sua estrutura urbana resultam, em larga medida, do acelerado processo de urbanização que experimentou na segunda metade do século XX. Piracicaba foi palco de expressivo crescimento demográfico e urbano ao longo das décadas de 1950, 1960 e 1970, processo altamente relacionado ao fato de que este foi um dos territórios que mais se beneficiou dos efeitos da desconcentração industrial da Grande São Paulo, caracterizando-se, a partir de então, como relevante polo industrial do interior paulista.

Esse desenvolvimento econômico do município teve, contudo, resultados muito desiguais no território, sendo apropriado de maneira desequilibrada entre os distintos segmentos sociais. Negri (1996) aponta que além das indústrias também os problemas das metrópoles migraram para os centros urbanos beneficiados pelo processo de desconcentração industrial e interiorização do desenvolvimento. Também Cano (2011) veio apontar que as cidades de porte médio que mais se beneficiaram dessa industrialização passaram a apresentar problemas urbanos antes exclusivos da metrópole.

Em 1970 a população total do município foi registrada em 152.505 habitantes, cerca de $84 \%$ dos quais na área urbana (IBGE, 2011). O crescimento populacional se fez acompanhar da expansão da urbanização, com a consequente periferização das camadas de baixa renda, relegadas às franjas da mancha urbana, em ocupações fragmentadas, descontínuas e subequipadas, onde eram evidentes "a pobreza, a precariedade habitacional e a presença de imóveis subnormais" (PÓLIS, 2003). Configurou-se, a partir de então, uma estruturação do território claramente marcada pelo padrão centro-periferia de localização das classes sociais, à semelhança de inúmeros municípios brasileiros de porte semelhante.

A partir de meados dos anos 1960 a favelização, fenômeno urbano até então desconhecido em Piracicaba, passou a marcar sua paisagem, fruto do acelerado crescimento populacional e da completa ausência de regulação e controle da 
ocupação, assim como de políticas públicas habitacionais, resultando no encarecimento do solo urbano. Segundo Funes (2005) a primeira favela de Piracicaba surgiu em 1965, na ocupação até hoje existente Jardim Algodoal, na região norte da cidade. No ano de 1979 a cidade contava com 22 núcleos de favelas, que abrigavam cerca de 10 mil pessoas. Para efeito de comparação, o Censo Demográfico de 1980 apontou para o município uma população total de 214.307 habitantes, dos quais 197.881 viviam na área urbana (IBGE, 2011), permitindo constatar que cerca de $5 \%$ dos residentes urbanos do município viviam em núcleos subnormais em 1979. Em 1992 já se contavam 53 favelas, onde residiam 22 mil pessoas (SIQUEIRA, 1993). Tomando-se por base apenas os residentes urbanos segundo o Censo de 1991 (269.961 habitantes), depreende-se que, no começo daquela década, aproximadamente $8 \%$ da população urbana vivia em favelas. No ano de 2017, dados do PMHIS - Plano Municipal de Habitação de Interesse Social (PIRACICABA, 2017) apontavam para 34.614 residentes em favelas, perfazendo pouco mais de $9 \%$ do total da população urbana; destes, 3.976 pessoas residiam nos dois únicos núcleos de aglomerados subnormais já regularizados do município. Ainda segundo esse mesmo estudo, os domicílios em favelas, em núcleos irregulares, totalizavam 6.107 unidades no ano de 2017 em Piracicaba.

Estes domicílios em favelas são parte expressiva do déficit habitacional verificado no município. A partir de dados do Censo Demográfico 2010, o estudo Déficit Habitacional Municipal no Brasil identificou a demanda por moradia em Piracicaba, concentrada nos estratos com ganhos de até três salários mínimos (incluídas as famílias sem rendimentos), onde se verifica a presença de $55 \%$ da demanda, como vemos na Tabela 1.

Tabela 1 - Déficit Habitacional Total e por faixas de renda (em Salários Mínimos) em 2010

\begin{tabular}{|l|c|c|c|c|c|}
\hline & Total & $\begin{array}{c}\text { Domicílios } \\
\text { sem } \\
\text { rendimento }\end{array}$ & $\begin{array}{c}\text { Domicílios com } \\
\text { rendimento } \\
\text { 0 a 3 S.M. }\end{array}$ & $\begin{array}{c}\text { Domicílios } \\
\text { com } \\
\text { rendimento } \\
\mathbf{3} \text { a 6 S.M. }\end{array}$ & $\begin{array}{c}\text { Domicílios } \\
\text { com } \\
\text { rendimento } \\
\mathbf{6} \text { a } 10 \text { S.M. }\end{array}$ \\
\hline $\begin{array}{l}\text { Unidades } \\
\text { habitacionais }\end{array}$ & 12.436 & 303 & 6.455 & 1.744 & 2.661 \\
\hline
\end{tabular}

Fonte: FJP - Fundação João Pinheiro. Organizado pelo autor.

Neste início de século XXI, contudo, assiste-se a uma mudança nos padrões de crescimento demográfico em todo o Brasil, e que se faz notar também em Piracicaba. Se o contexto das décadas finais do século XX era de expansão, a partir dos anos 2000 assiste-se a uma desaceleração do crescimento populacional, com importantes implicações em termos de políticas públicas e planejamento urbano. Como pode ser observado na Tabela 2, a partir dos anos 2000 Piracicaba passa a apresentar reduzidos índices de crescimento de sua população, em níveis inferiores aos de sua Região de Governo e da Região Administrativa de Campinas e, a grande novidade, inferior ao da média do estado de São Paulo. Esse fenômeno mantém-se como tendência e, nos anos 2010, o ritmo de crescimento se reduz ainda mais, atingindo os níveis mais baixos de sua história recente. 
Política habitacional e negócios imobiliários em Piracicaba...

Tabela 2 - Taxas Geométricas de Crescimento Anual da População - 1980/2018 (em $\%$ a.a.)

\begin{tabular}{|c|c|c|c|c|}
\hline & $\mathbf{8 0 / 9 1}$ & $\mathbf{9 1 / 0 0}$ & $\mathbf{0 0 / 1 0}$ & $\mathbf{1 0 / 1 8}$ \\
\hline Estado de São Paulo & 2,12 & 1,82 & 1,09 & 0,82 \\
\hline Região Administrativa de Campinas & 2,91 & 2,31 & 1,49 & 1,11 \\
\hline Região de Governo de Piracicaba & 2,70 & 2,00 & 1,20 & 0,83 \\
\hline Município de Piracicaba & 2,58 & 1,9 & 1,03 & 0,70 \\
\hline
\end{tabular}

Fonte: Censos Demográficos 1980, 1991, 2000 e 2010/IBGE; SEADE. Organizado pelo autor.

Tem-se, portanto, um novo contexto: ao passo que a cidade vem experimentando um processo que conduz à estagnação de seu crescimento populacional, o que aponta para um cenário de redução da demanda por habitação e urbanização, subsiste um persistente déficit habitacional, concentrado, fundamentalmente, nos estratos de mais baixa renda dentre seus cidadãos.

Como já observado, ainda que não devidamente analisado, Piracicaba foi palco de uma expressiva produção imobiliária nesse período recente. Em que medida essa explosiva produção de novas moradias e lotes urbanizados veio responder às reais demandas do município? Trataremos dessa produção na seção seguinte.

\section{PRODUÇÃO DO ESPAÇO URBANO, DEMANDA POR MORADIA E INTERESSES IMOBILIÁRIOS}

No município de Piracicaba, nos primeiros quinze anos do século $\mathrm{XXI}$, foram aprovados mais de uma centena de loteamentos, o que representou a produção de mais de 30 mil novos lotes. Esse número representa o quíntuplo dos lotes aprovados na década de 1980, e quase seis vezes mais que toda a produção em termos de parcelamento do solo dos anos 1990 (IPPLAP; MAIA, 2015; DUARTE, 2003). De 2010 a 2015, em termos de produção de novos loteamentos e número de lotes produzidos, a cidade figurou na segunda posição dentre todas as cidades paulistas, ficando atrás apenas de São José do Rio Preto nesse ranking (SECOVI/SP).

Como já observado na cidade se verificava, em 2010, um persistente déficit habitacional. Dada a aparente baixa produção de parcelamentos do solo ao longo das décadas de 1980 e 90, esse boom imobiliário experimentado a partir do século XXI poderia representar a resposta a uma demanda represada do período anterior. Entretanto, ao se analisar a evolução do número de lotes vazios na cidade ao longo desse período, observa-se que o estoque imobiliário, já alto no início dos anos 2000, só fez se elevar, como podemos ver na Tabela 3.

Tabela 3 - Lotes urbanos vazios em Piracicaba, segundo lançamento do Imposto Predial e Territorial Urbano (IPTU) - 2002 a 2017.

\begin{tabular}{|c|c|c|c|c|c|c|c|}
\hline $\mathbf{2 0 0 2}$ & $\mathbf{2 0 0 3}$ & $\mathbf{2 0 0 4}$ & $\mathbf{2 0 0 5}$ & $\mathbf{2 0 0 6}$ & $\mathbf{2 0 0 7}$ & $\mathbf{2 0 0 8}$ & $\mathbf{2 0 0 9}$ \\
\hline 30.979 & 31.180 & 32.213 & 33.931 & 36.244 & 34.895 & 36.145 & 34.710 \\
\hline
\end{tabular}


Política habitacional e negócios imobiliários em Piracicaba...

\begin{tabular}{|c|c|c|c|c|c|c|c|}
2010 & 2011 & 2012 & 2013 & 2014 & 2015 & 2016 & 2017 \\
\hline 35.951 & 38.270 & 40.466 & 42.968 & 42.560 & 44.285 & 44.152 & 43.351 \\
\hline
\end{tabular}

Fonte: Secretaria Municipal de Finanças/PMP. Organizado pelo autor.

Observava-se, no ano de 2002, a existência no município de pouco menos de 31 mil lotes urbanos vazios, já dotados de infraestrutura; após esse período de superprodução, os lotes vazios vão atingir a cifra de 43.351 em 2017. Destaque-se que, neste mesmo ano, o PMHIS vai mostrar que o número de famílias em favelas em Piracicaba sofre uma elevação.

Mapa 1 - Loteamentos aprovados em Piracicaba - 2001 a 2015

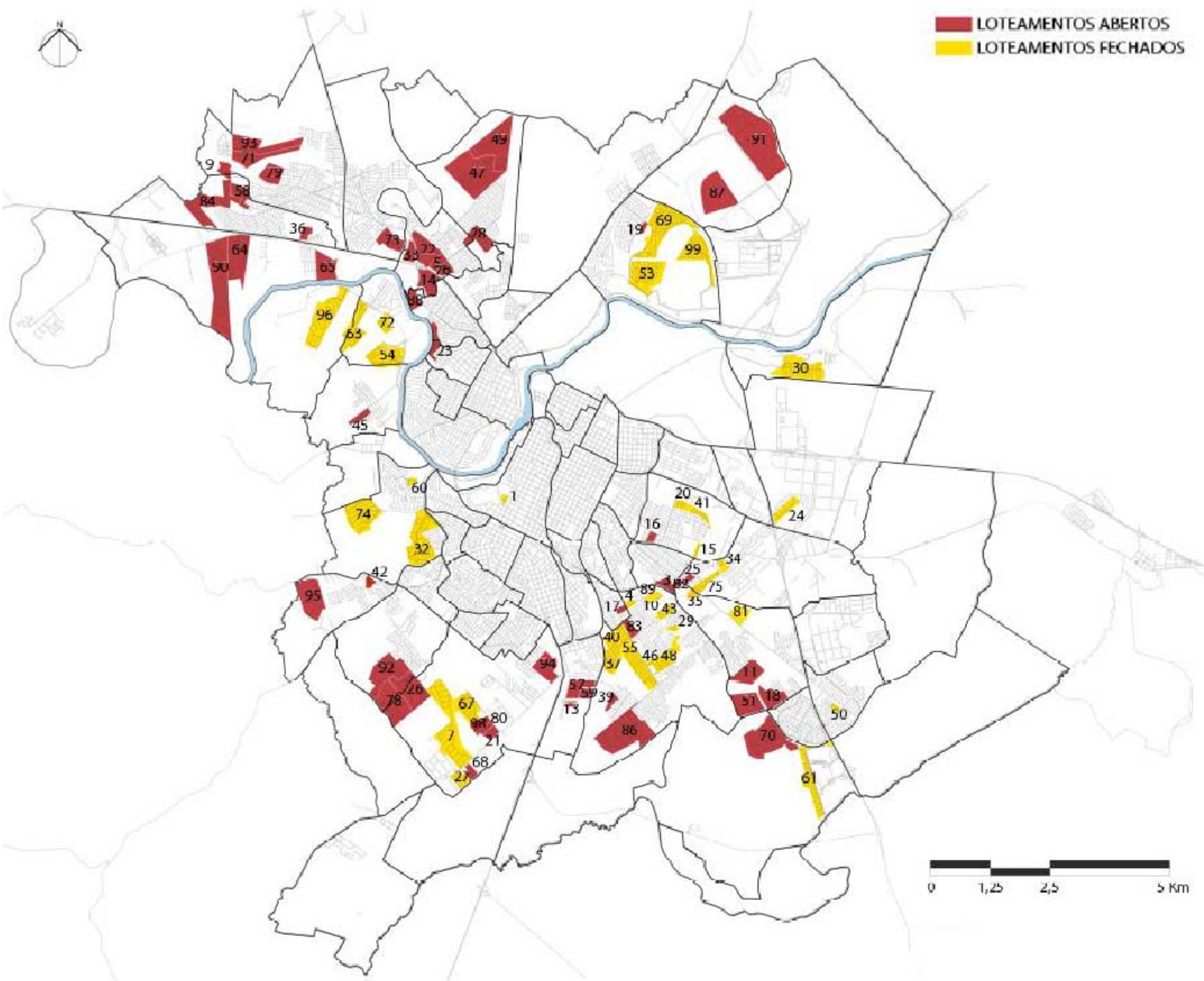

Fonte: CREPALDI, 2017. 
Tabela 4 - Loteamentos aprovados em Piracicaba entre 2001 e 2015

\begin{tabular}{|c|c|c|c|c|c|}
\hline ANO & MAPA & NOME LOTEAMENTO & ANO & MAPA & NOME LOTEAMENTO \\
\hline \multirow{2}{*}{2001} & 1 & Chácara São José & \multirow{2}{*}{2009} & 53 & Alphaville \\
\hline & 2 & Conjunto Habitacional " Água Branca l" & & 54 & Parque Residencial Damha I \\
\hline \multirow{2}{*}{2002} & 3 & Jardim Pombeva & \multirow{11}{*}{2010} & 55 & Residencial São Luiz \\
\hline & 4 & Jardim Água Viva & & 56 & Recanto da Água Branca \\
\hline 2003 & 5 & Parque Conceição & & 57 & Residencial Bertolucci * \\
\hline \multirow{7}{*}{2004} & 6 & Colibris Jardim & & 58 & Monte Rey III \\
\hline & 7 & Park Campestre & & 59 & Mont Carlo * \\
\hline & 8 & Residencial Recanto Feliz & & 60 & Terras de Piracicaba $V^{*}$ \\
\hline & 9 & Jardim Residencial Javary III & & 61 & Jardim Residencial UNIMEP * \\
\hline & 10 & Santa Laura & & 62 & Residencial Terras de Ártemis \\
\hline & 11 & Sol Nascente II * & & 63 & Residencial Reserva das Paineiras \\
\hline & 12 & Jardim Santa Maria & & 64 & Residencial Altos da Boa Vista* \\
\hline \multirow{11}{*}{2005} & 13 & Residencial Villa Real & & 65 & Parque das Águas \\
\hline & 14 & Jardim São Vicente & \multirow{10}{*}{2011} & 66 & Alphanorth Industrial \\
\hline & 15 & Residencial Humaitá & & 67 & Quinta do Campestre* \\
\hline & 16 & Jardim Reserva Imperial & & 68 & Residencial Vitória \\
\hline & 17 & Recanto do Astúrias & & 69 & Villa D'Áquila* \\
\hline & 18 & Terra Rica III & & 70 & Residencial Campos do Conde ${ }^{*}$ \\
\hline & 19 & São Gabriel & & 71 & Vem Viver Piracicaba I* \\
\hline & 20 & Terras do Sinhô I & & 72 & Ondas do Piracicaba \\
\hline & 21 & Jardim Laranjal & & 73 & Park Santa Terezinha \\
\hline & 22 & Parque Conceição II & & 74 & Morada do Engenho \\
\hline & 23 & Jardim Algodoal & & 75 & Villa D'Itália \\
\hline \multirow{2}{*}{2006} & 24 & Jardim Residencial Jatobás & \multirow{7}{*}{2012} & 76 & Jardim Residencial Cambuy \\
\hline & 25 & Jardim Panorama II & & 77 & Villaggio Paulino Martini \\
\hline \multirow{13}{*}{2007} & 26 & Jardim Santa Fé & & 78 & Jardim Santa Clara* \\
\hline & 27 & Parque dos lpês & & 79 & Jardim dos Manacás \\
\hline & 28 & Piracicaba C & & 80 & Jardim Laranjal \\
\hline & 29 & Residencial Gaivotas & & 81 & Convívio Residencial Lazuli Plaza* \\
\hline & 30 & Residencial Monte Alegre * & & 82 & Riviera Residence \\
\hline & 31 & Residencial Paulista & \multirow{6}{*}{2013} & 83 & Residencial Formaggio \\
\hline & 32 & Residencial Reserva do Engenho & & 84 & Altos do São Francisco* \\
\hline & 33 & Jardim São Vicente II & & 85 & Loteamento do Horto \\
\hline & 34 & Habitare Residencial & & 86 & Jardim Monte Feliz ${ }^{*}$ \\
\hline & 35 & Residencial Leão & & 87 & Parque Automotivo \\
\hline & 36 & Jardim Pacaembu & & 88 & Comercial Cristóvão Colombo \\
\hline & 37 & Residencial Portal da Água Branca & \multirow{11}{*}{2014} & 89 & Vilagio Clotilde Brossi \\
\hline & 38 & Jardim Helena & & 90 & Vivendas* \\
\hline \multirow{2}{*}{2008} & 39 & Conjunto Habitacional Altos da Água Branca * & & 91 & Uninorte $\|^{*}$ \\
\hline & 40 & Jardim Tomazella & & 92 & Jardim Piazza Itália* \\
\hline \multirow{12}{*}{2009} & 41 & Terras do Sinhô II & & 93 & Vem Viver Piracicaba II* \\
\hline & 42 & Santo Antonio II & & 94 & Terrazul KR* \\
\hline & 43 & Recanto do Piracicamirim & & 95 & Nova Suíça \\
\hline & 44 & Reserva do Engenho & & 96 & Vitória Régia* \\
\hline & 45 & Residencial Parque Santin & & 97 & Quinta do Campestre* \\
\hline & 46 & Santa Tereza D' Ávila & & 98 & Recanto Campestre \\
\hline & 47 & Bosques do Lenheiro & & 99 & Vila Bela Vista* \\
\hline & 48 & Nova Água Branca II & \multirow{5}{*}{2015} & 100 & Corporate Park Piracicaba \\
\hline & 49 & Jardim Gilda & & 101 & Recanto dos Jatobás \\
\hline & 50 & Convívio São Francisco & & 102 & Residencial Florinda \\
\hline & 51 & Altos do Taquaral * & & 103 & Residencial Ágape \\
\hline & 52 & Recanto Feliz I & & 104 & Jardim Santa Clara* \\
\hline
\end{tabular}

Fonte: IPPLAP apud CREPALDI, 2017

Temos, portanto, um aparente paradoxo na produção imobiliária nesse momento: a expressiva ampliação da oferta da mercadoria "lote urbanizado", num quadro de persistente déficit por moradia, não foi absorvida pelo mercado local, enquanto valor de uso, ou seja, restaram desocupados em larga medida. A crescente produção, com seguidos lançamentos de novos empreendimentos, permite entrever, no entanto, que essa mercadoria vinha sendo comercializada, 
vendida e comprada, no mercado local ${ }^{3}$. Outro elemento relevante à análise referese à tipologia de empreendimento que vai marcar esse momento: o "loteamento fechado", que veio representar pouco mais de um quarto de todos os lançamentos verificados no período (OTERO, 2016).

Como podemos ver no Mapa 1, esses novos parcelamentos tiveram impacto bastante significativo no território municipal, vindo representar uma expressiva expansão da mancha urbana, fortemente caracterizada pela dispersão da urbanização. No mesmo mapa podemos observar a distinção entre empreendimentos abertos e "fechados", ainda que estes tenham sido aprovados, invariavelmente, sob a forma de parcelamentos do solo para fins urbanos sob a égide da Lei Federal 6.766/79. Os empreendimentos encontram-se referenciados na Tabela 4, com seu respectivo ano de aprovação na Prefeitura do Município de Piracicaba.

Acompanhando essa superprodução em termos de parcelamento do solo veio se dar, a partir de 2009, uma crescente produção de unidades habitacionais, sob o marco da implantação do Programa Minha Casa Minha Vida (PMCMV). Até 31 de dezembro de 2016 foram contratadas, em Piracicaba, 16.161 moradias, nas três faixas do programa (DAMASCENO, 2017, p.108). Como vimos na Tabela 1, este número excede o apontado déficit habitacional para 2010.

Essa produção, no entanto, se deu de forma bastante desequilibrada em relação à demanda apontada no estudo sobre o déficit habitacional municipal. Como podemos ver na Tabela 5, quase três quintos da produção se concentrava na Faixa 2 do Programa, voltada a consumidores com renda entre 3 e 6 Salários Mínimos; as 9.430 unidades contratadas para essa faixa perfaziam $540 \%$ do que se apontava como déficit para esse perfil de renda no começo da década. A Faixa 1, onde se concentra o déficit por moradia no município - à semelhança das demais cidades brasileiras -, foi objeto de contratação de pouco mais de 3 mil novas unidades, não atingindo a metade da demanda.

Tabela 5 - PMCMV - Unidades Habitacionais Contratadas - por Faixa e proporção em relação ao déficit habitacional - Piracicaba, 2009 a 2016*

\begin{tabular}{lcccccccc} 
& $\begin{array}{c}\text { Unid. } \\
\text { Hab. } \\
\text { Faixa 1 }\end{array}$ & $\begin{array}{c}\text { Proporção } \\
\text { do Déficit } \\
\text { 0 a 3 S.M. }\end{array}$ & $\begin{array}{c}\text { Unid. } \\
\text { Fab. } \\
\text { Faixa 2 }\end{array}$ & $\begin{array}{c}\text { Proporção } \\
\text { do Déficit } \\
\text { 3 a 6 S.M. }\end{array}$ & $\begin{array}{c}\text { Unid. } \\
\text { Hab. } \\
\text { Faixa 3 }\end{array}$ & $\begin{array}{c}\text { Proporção } \\
\text { do Déficit } \\
\text { 6 a 10 S.M. }\end{array}$ & TOTAL $^{\text {Média }}$ \\
\hline Piracicaba & 3.056 & $(45,22 \%)$ & 9.430 & $(540,71 \%)$ & 3.675 & $(138,11 \%)$ & $\mathbf{1 6 . 1 6 1}$ & $\mathbf{2 . 1 5 5}$ \\
\hline
\end{tabular}

Fonte: MCidades; FJP - Déficit Habitacional Municipal no Brasil 2010; OTERO, 2016; DAMASCENO, 2017.

* Para cálculo das médias anuais considerou-se os empreendimentos que tiveram contrato celebrado entre julho de 2009, com a instituição do programa, e 31 de dezembro de 2016, período coberto por este levantamento, perfazendo o intervalo de 7,5 anos.

A partir desses dados é possível identificar, ainda, que a produção realizada sob a égide do PMCMV ultrapassou a demanda verificável pelo estudo da FJP, caracterizando-se pelo desequilíbrio na oferta. Mesmo a produção para a Faixa 3 do Programa apresenta-se superavitária. Muito mais que uma atuação efetiva no

\footnotetext{
${ }^{3}$ Crepaldi (2017), em pesquisa que será discutida mais à frente, demonstra as lógicas de que se reveste essa superprodução e as funções desempenhadas pela terra urbana nesse período.

Estudos Geográficos, Rio Claro, 15(2): p-p, jul./dez. 2017 (ISSN 1678-698X)

http://www.periodicos.rc.biblioteca.unesp.br/index.php/estgeo
} 
enfrentamento do problema da moradia, a produção do PMCMV no município, assim como em outras cidades médias paulistas (OTERO, 2016), voltou-se a uma demanda solvável, restando sem atendimento os segmentos sociais mais carentes.

Cabe ressaltar que esse boom imobiliário foi fortemente apoiado por instrumentos legais da política urbana municipal. Entre a aprovação da Lei Complementar 186/06, que instituiu o novo Plano Diretor do município, e o ano de 2016, o perímetro urbano foi ampliado em nada menos que dez oportunidades, convertendo terras rurais em área urbanizável e viabilizando, legalmente, a dispersão da urbanização. Destaque-se que uma das diretrizes daquele PD era, justamente, o congelamento do perímetro urbano, visto que a Zona Urbana àquele momento já apresentava grande quantidade de glebas desocupadas (PÓLIS, 2003). As seguidas ampliações do perímetro vieram aumentar a área urbana do município em mais de 30\%, no decurso desses dez anos (OTERO, 2016; GOULART et al., 2013; OTERO, 2011).

Além disso, as ZEIS 2 - Zonas Especiais de Interesse Social ${ }^{4}$, destinadas à produção de novas moradias, também vicejaram no período: entre 2009, ano da regulamentação do instrumento, e 2016, quando da aprovação da ZEIS 2 AA, da qual trataremos mais detidamente, foram demarcados 27 perímetros, todos, invariavelmente, nas franjas das área urbanizada, quando não em terrenos originalmente rurais, em zonas marcadas por precariedade de infraestrutura, fragilidade ambiental, quando não ambos. Podemos observar a expansão do perímetro urbano entre 2006 e 2016 no Mapa 2, assim como a localização dos 27 perímetros de ZEIS 2 do município.

No mapa fica clara de que maneira a política urbana efetivamente implantada em Piracicaba nesse intervalo, entre a aprovação do PD e a demarcação da ZEIS 2 AA - Corumbataí, concorreu decisivamente para descaracterizar o próprio diagnóstico do Plano, incentivando a dispersão e acirrando a fragmentação do território.

A própria demarcação de ZEIS 2 em glebas que, ao ano da aprovação do PD constituíam-se em áreas rurais, aponta para o papel que a própria produção de habitação de interesse social desempenhou no processo de urbanização local no último período, após a instituição do PMCMV. Diversas pesquisas e autores (SANTO AMORE et al., 2015; CARDOSO, 2013; FERREIRA, 2012) já apontaram que essa tônica foi dominante na implementação do Programa Brasil afora.

O que nos interessa apontar aqui é a expressiva atividade imobiliária, tanto em termos de novos lotes urbanizados quanto de unidades prontas, que se abateu sobre Piracicaba no último período. Essa produção extrapolou, em muito, a própria demanda verificável no município. O persistente déficit habitacional local, cuja mais perfeita tradução se verifica na sua favelização, não é fruto da escassez de espaço urbano, mas sim da condição social daqueles segmentos que seguem sem meios de acessar a mercadoria habitação.

\footnotetext{
${ }^{4}$ As ZEIS para áreas vazias, destinadas à promoção de habitação de interesse social, tem por objetivo aumentar a oferta de terras para os segmentos urbanos de baixa renda (BRASIL, 2002). Entretanto, e sobretudo após a promulgação do PMCMV, estas vêm sendo largamente utilizadas para a viabilização de empreendimentos do Programa em localizações periféricas (OTERO, 2016).
} 
Mapa 2 - Piracicaba - Ampliação do perímetro urbano 2006 - 2016 e ZEIS 2

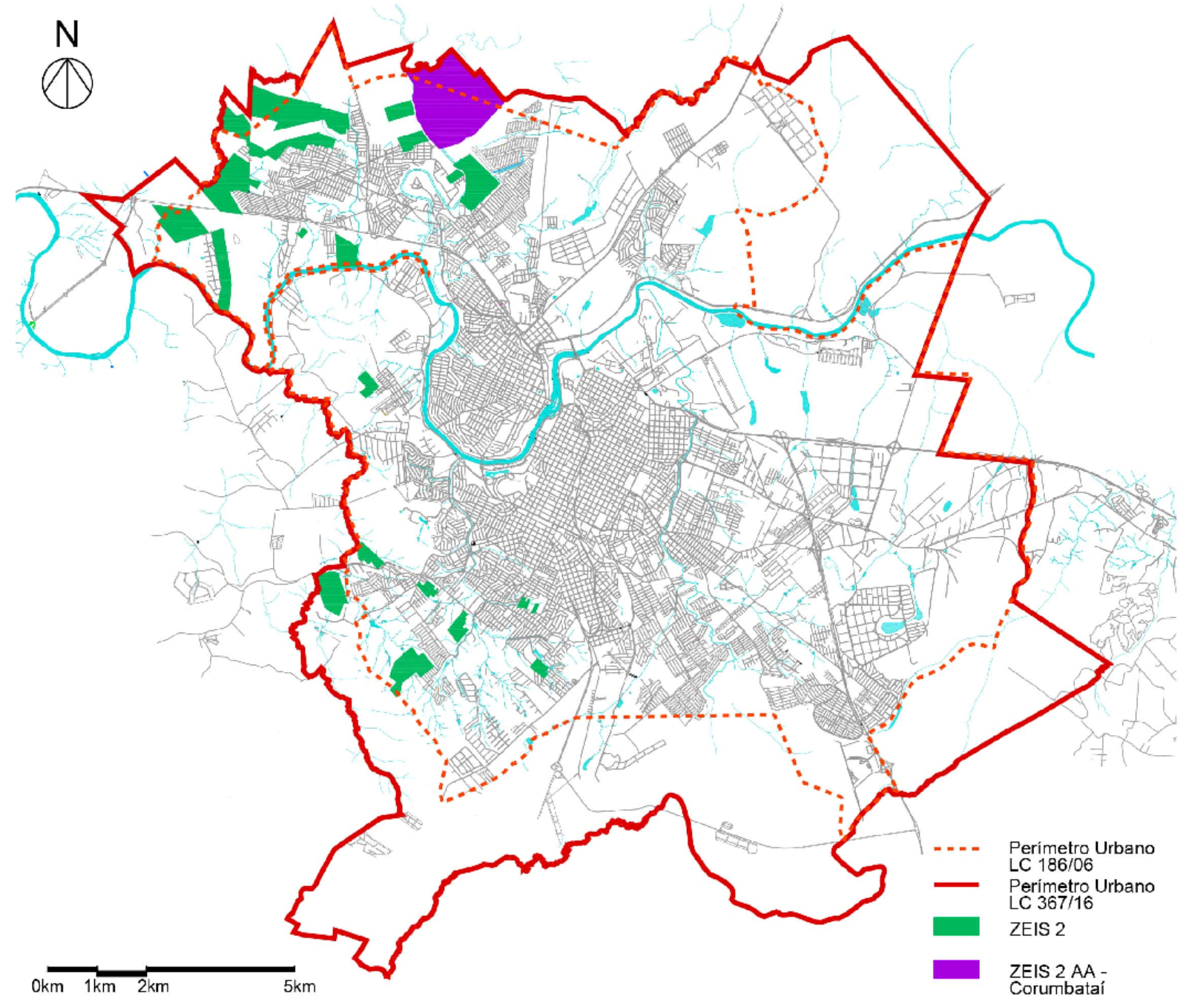

Fonte: IPPLAP. Elaborado pelo autor.

Entretanto, se a produção de terra urbanizada vem ultrapassando largamente a demanda, fato demonstrando pela ampliação do estoque de lotes vazios, e as unidades do PMCMV excederam as necessidades habitacionais que se verificavam no começo da década, o que justificaria essa superprodução? E, questão correlata, já que existe um excesso de oferta, de que modo se comportou a evolução dos valores imobiliários neste início de século XXI?

Crepaldi (2017), em estudo sobre a evolução do preço da terra urbanizada em Piracicaba entre 2001 e 2015, constata que a referida superprodução, menos que resposta à demanda existente, decorreu da formação de uma ampla

[...] coalização de interesses entre os agentes público e privados, onde os primeiros viabilizam a atividade do parcelamento ao tornar glebas de baixa valoração comercial em áreas aptas ao parcelamento, por meio de sua incorporação ao perímetro urbano, possibilitando maior extração de renda pelos agentes imobiliários (CREPALDI, 2017, p.91). 
A partir de levantamento empírico de pouco mais de 22 mil anúncios de revenda de lotes veiculados na imprensa local, identificou-se um contínuo aumento dos valores fundiários, a par com a explosão da implantação de novos parcelamentos do solo no município. No intervalo entre 2001 e 2015, a valorização da terra variou, conforme sua localização, entre 1000\% (na região Centro) até aproximadamente $2500 \%$ (nos "loteamentos fechados" da região Norte).

Essa valorização, superando diversos índices econômicos no mesmo período, vem apontar

[...] para o papel do solo urbano como reserva de valor e bom investimento aos capitais excedentes. A segurança desse tipo de investimento, ainda que apresente pouca liquidez, associada aos baixos custos envolvidos em sua "manutenção" e administração, ajuda a lançar luz sobre os motivos que o tornam atrativo.

Por essa razão, [...] a superprodução do parcelamento do solo no município de Piracicaba não se vê necessariamente associada ao consumo imediato dessa mercadoria imobiliária, mas às perspectivas econômicas que a envolvem. (CREPALDI, 2017, p.91-92).

Portanto, o quadro que se verificava em Piracicaba, ao fim da segunda década do século XXI, era de um excesso de oferta de espaço urbano, e mesmo de unidades prontas implantadas no bojo do PMCMV, num contexto de intensa valorização imobiliária. Totalmente desvinculada das demandas dos estratos de baixa renda, excluída desse mercado imobiliário formal, essa produção respondeu muito mais aos interesses dos empreendedores e, também, como mostra Crepaldi, dos consumidores que tomaram o espaço urbano como um excelente investimento.

\section{OPERAÇÃO URBANA CONSORCIADA CORUMBATAÍ: O DÉFICIT HABITACIONAL E A "MÁQUINA DO CRESCIMENTO"}

Objeto especial de nossa atenção, a Operação Urbana Corumbataí, proposta pelo Executivo Municipal por meio do Projeto de Lei Complementar 015/17 tem, dentre seus objetivos, "produzir unidades habitacionais de interesse social para o atendimento da demanda habitacional de interesse social existente no Município de Piracicaba" (Art $4^{\circ}$, Inciso I). A princípio meritória enquanto pressuposto, a proposta carrega uma série de problemas e contradições; o primeiro deles tendo origem diretamente na própria definição do instrumento utilizado para a viabilização da proposta.

Como mostra Wanderley (2017), o conceito de que se revestem as operações urbanas foi introduzido no Brasil nos anos de 1980, nas discussões para a formulação do Plano Diretor de São Paulo à época. Diante de severas restrições orçamentárias ao financiamento do desenvolvimento urbano, a ideia da parceria público-privada parecia alvissareira. A crescente aceitação desse tipo de concertação entre o Estado e a iniciativa privada, notadamente os agentes da produção do espaço, deve-se ao fato que de, por meio desse tipo de parceria, seria estabelecida "uma forma de superação das dificuldades [financeiras] que o Estado enfrenta" (WANDERLEY, 2017, p.39). No entanto, dada a profunda desigualdade que marca a sociedade brasileira, espacialmente refletida nas nossas cidades, em que grande parte da população encontra-se alijada do mercado imobiliário formal, a 
experiência das Operações Urbanas, orientada aos interesses dos empreendedores imobiliários, acabou por reforçar nossa urbanização segregadora e excludente (Idem, p.40).

Segundo o Estatuto da Cidade (Lei Federal 10.257/01), onde se regulamenta o instrumento das Operações Urbanas Consorciadas, esta seria caracterizada como o "conjunto de intervenções e medidas coordenadas pelo Poder Público municipal, com a participação dos proprietários, moradores, usuários permanentes e investidores privados, com o objetivo de alcançar em uma área transformações urbanísticas estruturais, melhorias sociais e a valorização ambiental" (Art. $32, \S 1^{\circ}$ ).

As Operações Urbanas Consorciadas, da forma como foram regulamentadas no Estatuto da Cidade e como vêm sendo implementados no Brasil nas últimas três décadas, preveem dois tipos de medidas: I - a modificação de índices e características de parcelamento, uso e ocupação do solo e subsolo, bem como alterações das normas edilícias, considerado o impacto ambiental delas decorrente; e II - a regularização de construções, reformas ou ampliações executadas em desacordo com a legislação vigente ((Art. 32, § $\left.2^{\circ}\right)$.

A proposta constante do PLC 015/17 não se enquadra em nenhuma dessas situações, uma vez que a área para a qual se propõe o instrumento trata-se de área rural, descontínua em relação ao tecido urbano consolidado da cidade de Piracicaba ${ }^{5}$. A integralidade do perímetro da ZEIS 2 AA - Corumbataí, na realidade, só foi incorporado à Zona Urbana do município no ano de 2016, por meio da Lei Complementar 367/16, com a ampliação do perímetro urbano englobando toda a porção norte da referida área. Numa cidade cuja urbanização sempre foi marcada por grande número de vazios e descontinuidades territoriais, em que mais da metade da área urbana se encontra sem urbanização, a ampliação mesma se tornava injustificável. Essa condição periférica da área, assim como sua inserção rural até a mudança do perímetro em 2016 pode ser observada no Mapa 2.

A criação da ZEIS 2 AA - Corumbataí se fez de forma concomitante à sua incorporação ao perímetro urbano de Piracicaba. O PLC 4/16 (que propõe a instituição da ZEIS 2 AA) e o PLC 5/16 (que propõe a ampliação do perímetro urbano justamente naquele território) foram protocolados, ambos, no dia 2 de fevereiro de 2016, sendo aprovados pelo Legislativo Municipal também, ambos, em conjunto, no dia $1^{\circ}$ de abril de 2016, este sob a forma da LC 367/16 e aquele da LC $368 / 16$.

Devidamente incorporada ao perímetro urbano e regulamentada como Zona Especial de Interesse Social 2 AA, a gleba veio a ser objeto do PLC $015 / 17$, de $1^{\circ}$ de setembro de 2017, com vistas à implantação de cerca de 3.500 unidades habitacionais, enquadradas na Faixa 1,5 do PMCMV ${ }^{6}$. A proposta apresenta, dentre as diretrizes a nortear o projeto, o objetivo de "fomentar uma urbanização crescente no bairro Corumbataí, de forma organizada e planejada, inserindo melhorias no entorno com ocupação já consolidada" (PLC 015/17, Art. 5², Inciso I). Como apontamos, trata-se de área rural, marcada pelo cultivo de cana de açúcar, em que se faz ausente qualquer tipo de ocupação urbana. Mesmo a ocupação do entorno só

\footnotetext{
${ }^{5}$ Instrumento muito mais adequado à situação aqui analisada seria a "Outorga Onerosa do Direito de Construir e Alteração de Uso" (Lei Federal 10.257/01, Art. 28 a 31), onde se prevê a prestação de contrapartidas do beneficiário da mudança de uso de uma área, como no caso, de rural para urbana.

${ }^{6}$ A informação quanto ao enquadramento na Faixa 1,5 do PMCMV foi fornecida pelo presidente do IPPLAP, Arthur Ribeiro Neto, em Audiência Pública sobre o PLC na Câmara de Vereadores de Piracicaba realizada em 20 de fevereiro de 2018.

Estudos Geográficos, Rio Claro, 15(2): p-p, jul./dez. 2017 (ISSN 1678 — 698X)

http://www.periodicos.rc.biblioteca.unesp.br/index.php/estgeo
} 
se realizou por meio da implantação de conjuntos habitacionais de iniciativa pública: o Mário Dedini (1994), Bosques do Lenheiro (1997) e Jd. Gilda (2006) (MAIA, 2015; OTERO, 2016). Ou seja, ao longo dos últimos 24 anos a expansão urbana naquele setor da cidade só se realizou através de ações habitacionais promovidas pelo poder público municipal.

Tal proposta, para a região em análise, apresenta problemas de duas ordens principais: ambiental e de vulnerabilidade social. A primeira delas, referente às fragilidades ambientais, resulta de que aquela porção norte do território piracicabano, está inscrita no Zoneamento Urbano como uma ZOCFA - Zona de Ocupação Controlada por Fragilidade Ambiental. A caracterização da Zona, no Artigo 49 do PD, já desaconselha o tipo de empreendimento que lá se propõe, ao afirmar que esta é representada por áreas "que embora possuam condições de infraestrutura, apresentam fragilidades ambientais, com solo sujeito a altos índices de erosão, não recomendável para o adensamento populacional".

Em relação à vulnerabilidade social, estudo elaborado pela Fundação Seade e Assembleia Legislativa de São Paulo, denominado IPVS - Índice Paulista de Vulnerabilidade Social, aponta aquele quadrante da cidade como um dos principais bolsões de vulnerabilidade do município, como podemos ver no Mapa 3, em que os setores ali localizados se caracterizam como de Grupo 5 - Alta Vulnerabilidade Social $^{7}$. Sobreponde condições de baixa escolaridade, e altos índices de pobreza e precariedade, resultado da concentração de empreendimentos habitacionais de interesse social num mesmo setor da cidade, este já representa, hoje, uma das mais agudas problemáticas sociais e de segurança pública do município.

Antevê-se profundos impactos decorrentes da implantação desse empreendimento proposto na ZEIS 2 AA - Corumbataí, uma vez que o porte desse empreendimento prevê população equivalente ao dos outros três conjuntos habitacionais supracitados, em sua totalidade ${ }^{8}$. Dado o perfil de ocupação do empreendimento proposto, em tudo semelhante à ocupação do entorno, é previsível uma ampliação da escala dos problemas sociais que ora já são visíveis na região.

7 Os setores censitários com pelo menos 50 domicílios particulares permanentes são classificados em um dos sete grupos: Grupo 1 - baixíssima vulnerabilidade; Grupo 2 - vulnerabilidade muito baixa; Grupo 3 vulnerabilidade baixa; Grupo 4 - vulnerabilidade média; Grupo 5 - vulnerabilidade alta; Grupo 6 - vulnerabilidade muito alta, correspondendo aos aglomerados subnormais e Grupo 7 - setores censitários rurais de alta ou muito alta vulnerabilidade.

${ }^{8}$ Segundo dados do IPPLAP, organizados a partir do Censo Demográfico de 2010, residiam no Bairro Mário Dedini, onde se localizam os conjuntos Mário Dedini, Bosques do Lenheiro e Jd. Gilda, 16.654 habitantes àquele ano; o projeto para a ZEIS 2 AA prevê uma população ao término do empreendimento de 13.992 residentes.

Estudos Geográficos, Rio Claro, 15(2): p-p, jul./dez. 2017 (ISSN 1678-698X)

http://www.periodicos.rc.biblioteca.unesp.br/index.php/estgeo 
Mapa 3 - Piracicaba - Índice Paulista de Vulnerabilidade Social 2010

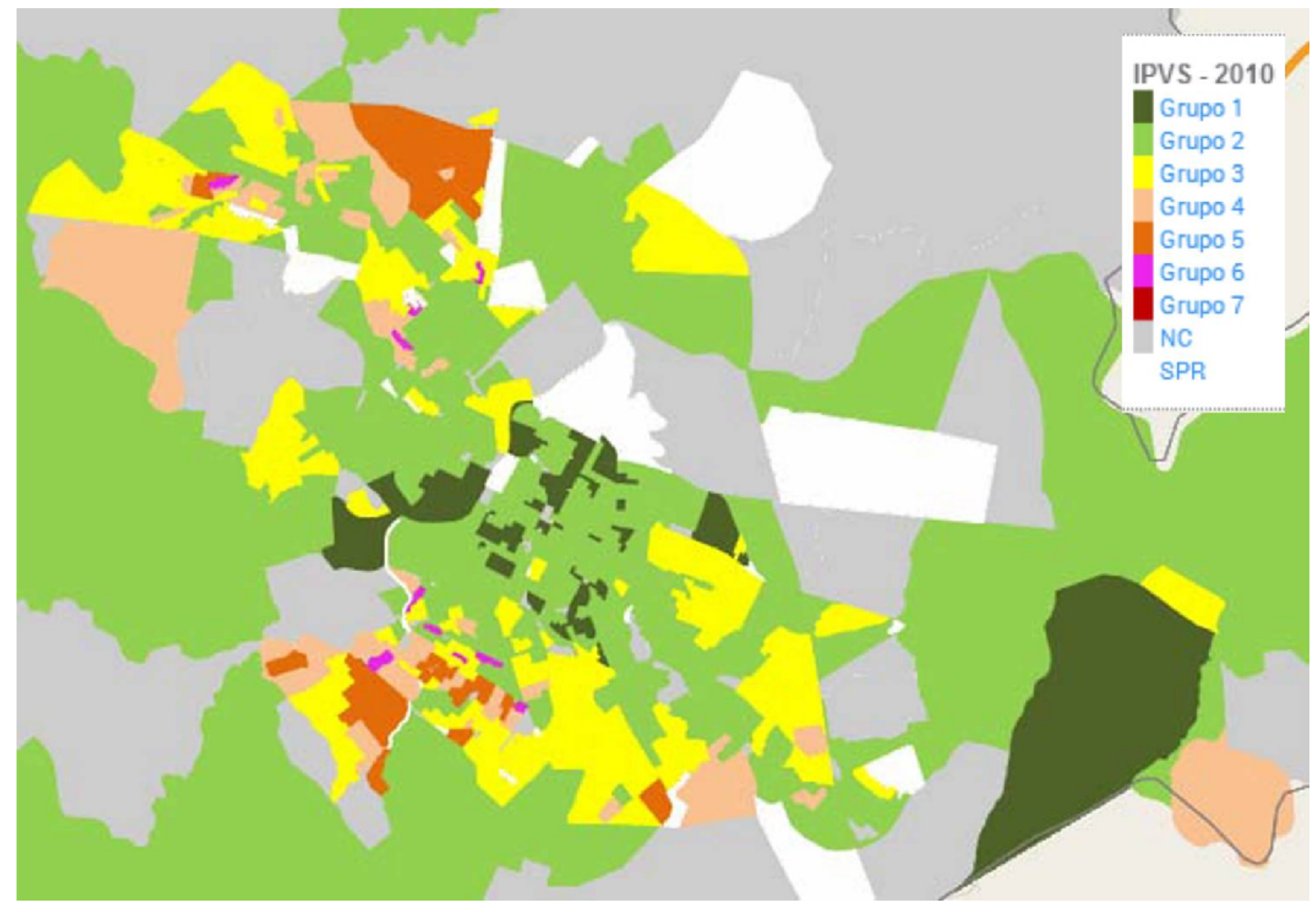

Fonte: ILP/Alesp; Seade.

Ainda que seja verificável que a demanda habitacional dos setores de mais baixa renda permanece sem atendimento, esta não se trata de resposta adequada, uma vez que promoverá a concentração de segmentos populares socialmente vulneráveis num setor restrito do território.

Como apresentamos ao longo deste artigo, Piracicaba se caracterizou ao longo do último período por uma superprodução de espaço urbano, inclusive no âmbito do PMCMV. Os segmentos que compõem o persistente déficit habitacional do município representam, na verdade, aqueles grupos alijados do mercado imobiliário formal, e que hoje se encontram nas favelas locais, para o que a presente proposta não representa alternativa consistente.

As engrenagens da "máquina de crescimento" local, no entanto, encontram-se em movimento no sentido de viabilizar a proposta, por meio da estruturação dessa parceria público-privada, que vem articular uma coalizão de interesses com foco no imobiliário (LOGAN; MOLOTCH, 2007). Estes autores notam, inclusive, de que maneira o crescimento urbano é, comumente, "vendido" como de interesse da coletividade:

[...] faz-se crer que incrementos na atividade econômica ajudam toda a comunidade. $\mathrm{O}$ crescimento, de acordo com esse argumento, traz empregos, expande a base tributária e paga por serviços urbanos. Governos municipais são, portanto, aconselhados a fazer todo o possível para atrair investidores (LOGAN; MOLOTCH, 2007, p. 33. Tradução do autor). 
No caso em tela, essa argumentação permeia toda a defesa da proposta. Em artigo publicado no jornal Gazeta de Piracicaba9 ${ }^{9}$, o Conespi - Conselho das Entidades Sindicais de Piracicaba, vem manifestar seu apoio à proposta da Operação Urbana em função da previsão de geração de 600 empregos diretos e 1.200 indiretos com as obras do empreendimento. Evidentemente, tais empregos seriam gerados de qualquer maneira caso essas moradias fossem construídas em qualquer outro local, ou mesmo na urbanização das favelas do município. O ponto central no empreendimento é a extração das rendas fundiárias decorrentes da conversão das terras agrícolas em urbanas. Seus impactos, porém, serão sentidos e administrados pela totalidade da sociedade piracicabana.

\section{CONSIDERAÇÕES FINAIS}

Como procuramos demonstrar ao longo deste artigo, a proposta da Operação Urbana Consorciada Corumbataí é repleta de contradições. Sua justificativa central, referente à demanda por habitação social no município é coerente, mas não se sustenta devido aos impactos sociais e ambientais resultantes da implantação de empreendimento de tal envergadura.

Como vimos, o persistente déficit habitacional não é fruto de subprodução de espaço urbano, muito pelo contrário. A cidade de Piracicaba, no período recente, foi palco de um boom imobiliário que vem promovendo ampla reestruturação de seu território. O ponto aqui é que essa produção, estreitamente vinculada à lógica do espaço enquanto mercadoria e investimento, mantém alijados da cidade formal amplos segmentos sociais da cidade.

A superprodução imobiliária, associada ao vertiginoso aumento dos valores da terra, decorreu num surpreendente paradoxo: quanto mais se produzia espaço urbano, mais distantes do acesso à cidade formal ficavam os estratos de baixa renda da população piracicabana.

Além disso, os impactos decorrentes de tal empreendimento seriam altamente perniciosos, dados seus custos ambiental e, como procuramos demonstrar, social. Ressalte-se que a constituição de bolsões de pobreza e vulnerabilidade social, resultado de políticas habitacionais equivocadas e pouco refletidas, quer seja nos empreendimentos da Cohab/SP nos extremos da Zona Leste paulistana, como Cidade Tiradentes, quer seja na banlieue parisiense, já foram amplamente criticados e revistos, sendo unanimemente desaconselhados por estudiosos do assunto. Em síntese, a aprovação de empreendimento desse porte, nessa localização, consumará uma evidente tragédia urbanística, ambiental e social.

A questão central, portanto, é identificar a raiz do problema da negação do direito à cidade a uma parcela tão ampla da sociedade piracicabana. O foco da questão, muito menos que na produção habitacional em si, deve se voltar à política urbana como um todo. As seguidas descaracterizações do arcabouço urbanístico legal concorreram ao acirramento das contradições na produção da cidade, impedindo a construção de uma cidade mais justa e democrática. É para a política urbana municipal, especialmente no que diz respeito ao atendimento às demandas

\footnotetext{
${ }^{9}$ Gazeta de Piracicaba. "Apoio do Conespi à Operação Corumbataí". 12 de março de 2018. Disponível em <http://www.gazetadepiracicaba.com.br/_conteudo/2018/03/home/532945-apoio-do-conespi-a-operacaocorumbatai.html>. Acesso em 18 de março de 2018.

Estudos Geográficos, Rio Claro, 15(2): p-p, jul./dez. 2017 (ISSN 1678-698X)

http://www.periodicos.rc.biblioteca.unesp.br/index.php/estgeo
} 
dos moradores de áreas precárias, irregulares e subnormais, que deveriam se voltar os olhos da sociedade.

\section{REFERÊNCIAS BIBLIOGRÁFICAS}

BRASIL. Estatuto da cidade: guia para implementação pelos municípios e cidadãos. Brasília: Câmara dos Deputados/Coordenação de Publicações, 2002.

CANO, W. Questão Regional e Urbanização no Desenvolvimento Econômico Brasileiro Pós-1930. In: CANO, W. Ensaios sobre a crise urbana do Brasil. Campinas: Ed. Unicamp, 2011.

CARDOSO, A.L. (Org.). O Programa Minha Casa Minha Vida e seus Efeitos Territoriais. Rio de Janeiro: Letra Capital, 2013.

CREPALDI, B. 2017. Boom Imobiliário e Evolução do Preço da Terra em Piracicaba (2001-2015). Relatório Final de Pesquisa de Iniciação Científica em Arquitetura e Urbanismo apresentado à Universidade Metodista de Piracicaba. (Unimep; CNPq - Piracicaba/Brasil).

DAMASCENO, B.C. Alternativas Habitacionais para Realidades NãoMetropolitanas: diversidade e heterogeneidade na provisão de moradias. 2017. Trabalho final de graduação em Arquitetura e Urbanismo apresentado à Universidade Metodista de Piracicaba. (Unimep - Piracicaba/Brasil).

DUARTE, L.N.R. O Processo de Urbanização de Piracicaba: estudo dos Planos Diretores - 1971-1991. 2003. Dissertação de Mestrado em Arquitetura e Urbanismo apresentada à Pontifícia Universidade Católica de Campinas. (FAU/PUCCampinas Campinas/Brasil).

FERREIRA, J.S.W. (Coord.). Produzir Casas ou Construir Cidades? Desafios para um novo Brasil urbano. São Paulo: LABHAB; FUPAM, 2012.

FIX, M.A.B. Financeirização e Transformações Recentes no Circuito Imobiliário no Brasil. 2011. Tese de Doutorado em Economia apresentada à Universidade Estadual de Campinas. (IE/Unicamp - Campinas/Brasil).

GOULART, J.O.; TERCI, E.T.; OTERO, E.V. A Dinâmica Urbana de Cidades Médias do Interior Paulista sob o Estatuto da Cidade. In: Revista Brasileira de Estudos Urbanos e Regionais, Vol 15 NN$^{\circ} 1$, Maio de 2013.

HARVEY, D. Cidades Rebeldes: do direito à cidade à revolução urbana. São Paulo: Martins Fontes - selo Martins, 2014.

HARVEY, D. Os Limites do Capital. São Paulo: Boitempo, 2013.

HARVEY, D. O Enigma do Capital. São Paulo: Boitempo, 2011.

LOGAN, J.; MOLOTCH, H. Urban Fortunes: the political economy of place. Los Angeles: University of California Press, 2007.

FJP - Fundação João Pinheiro. Déficit Habitacional Municipal no Brasil 2010. Belo Horizonte: CEl/FJP, 2013.

FUNES, S.M. Regularização Fundiária no Município de Piracicaba: ações e conflitos. 2005. Dissertação de Mestrado defendida no Programa de PósGraduação em Engenharia Urbana da Universidade Federal de São Calos. (UFSCar - São Carlos/Brasil). 
IBGE. Evolução da Divisão Territorial do Brasil: 1872-2010. Rio de Janeiro: IBGE, 2011.

IBGE. Regiões de Influência das Cidades - 2007. Rio de Janeiro: IBGE, 2008.

MAIA, A. Piracicaba: produção do espaço urbano. 2015. Trabalho final de graduação em Arquitetura e Urbanismo apresentado à Universidade Metodista de Piracicaba. (Unimep - Piracicaba/Brasil).

NEGRI, B. Concentração e Desconcentração Industrial em São Paulo (18801990). Campinas: Ed. Unicamp, 1996.

OTERO, E.V. Reestruturação Urbana em Cidades Médias Paulistas: a cidade como negócio. 2016. Tese de Doutorado em Arquitetura e Urbanismo apresentada à Universidade de São Paulo (FAU USP - São Paulo/Brasil).

OTERO, E.V. Expansão urbana no município de Piracicaba entre 2000 e 2010: políticas públicas e atividade imobiliária. In: Anais do XIV Encontro da Anpur. Rio de Janeiro, 2011.

PIRACICABA. Plano Municipal de Habitação de Interesse Social. Piracicaba: PMP, 2017.

PÓLIS. Relatório 1 - Leitura Técnica e Participativa. Revisão do Plano Diretor de Desenvolvimento de Piracicaba. Piracicaba: Pólis, 2003.

SANTO AMORE, C.; SHIMBO, L.Z.; RUFINO, M.B.C. (Orgs.). Minha Casa... e a Cidade? Avaliação do Programa Minha Casa Minha Vida em Seis Estados Brasileiros. Rio de Janeiro: Letra Capital, 2015.

SECOVI-SP. Estudo do Mercado Imobiliário de Piracicaba (2012 a 2015). Disponível em: <http://www.secovi.com.br/pesquisas-e-indices/>. Acesso em 15 de março de 2017.

SIQUEIRA, E.S. A Gestão de Projetos e a Produção da Cidadania na Associação dos Favelados de Piracicaba. 1993. Dissertação de Mestrado apresentada à Pontifícia Universidade Católica de São Paulo. (PUC-SP - São Paulo/Brasil).

WANDERLEY, B.S. Operação Urbana Consorciada: intervenção urbanística de requalificação ou projeto urbano excludente? 2017. Trabalho final de graduação em Arquitetura e Urbanismo apresentado à Universidade Metodista de Piracicaba. (Unimep - Piracicaba/Brasil). 